\title{
Kondisi Perairan Pantai Jelenga Sumbawa Barat sebagai Area Budidaya Rumput Laut Kappaphycus alvarezii
}

\author{
Environmental Conditions of Jelenga Beach, West Sumbawa as Seaweed \\ Kappaphycus alvarezii Cultivation Area \\ Erwansyah $^{1^{*}}$, Nunik Cokrowati $^{2^{*}}$, Sunaryo $^{3}$ \\ ${ }^{1}$ Prodi Teknik Pertambangan, Fakultas Teknik Cordova, Taliwang, Sumbawa Barat, NTB \\ ${ }^{2}$ Prodi Budidaya Perairan, Fakultas Pertanian, Universitas Mataram, Mataram, NTB \\ ${ }^{3}$ Dinas Kelautan dan Perikanan Kabupaten Sumbawa Barat, Taliwang, Sumbawa Barat, NTB \\ email:erwansyah01@icloud.com; nunikcokrowati@unram.ac.id
}

(Received: 21 Juni 2021; Accepted: 07 Juli 2021)

\begin{abstract}
ABSTRAK
Budidaya rumput laut dapat dilakukan pada perairan yang memiliki kondisi lingkungan yang sesuai dengan habitat rumput laut. Kappaphycus alvarezii merupakan jenis rumput laut yang tergolong alga merah penghasil karaginan yang dibudidayakan di perairan Indonesia termasuk di Pulau Sumbawa. Budidaya rumput laut K.alvarezii mulai dilakukan kembali pada tahun 2020 di perairan pantai Jelenga yang terletak di Kabupaten Sumbawa Barat. Metode budidaya yang digunakan adalah metode patok dasar dengan memanfaatkan area pasang surut yang masih tetap terendam air pada saat surut terendah. Tujuan penelitian ini adalah untuk mengetahui kondisi lingkungan perairan pantai Jelenga saat ini untuk area budidaya rumput laut $K$. alvarezii. Kondisi lingkungan tersebut diantaranya adalah kualitas air lokasi budidaya. Penelitian ini menggunakan metode survei langsung di lokasi penelitian. Hasil penelitian menunjukkan bahwa perairan pantai Jelenga memiliki kisaran suhu $29,2-29,8^{\circ} \mathrm{C}$, pH 7,2-7,1, salinitas 32-34 ppt, oksigen terlarut 5,2-7,8 $\mathrm{mg} / \mathrm{L}$, nitrat $11-12,7 \mathrm{mg} / \mathrm{L}$, fosfat $0,004-0,12 \mathrm{mg} / \mathrm{L}$, dan kecepatan arus 7,2-16 $\mathrm{cm} /$ detik. Kesimpulan penelitian ini adalah kondisi lingkungan perairan pantai Jelengah saat ini sesuai dengan lingkungan yang disayaratkan sebagai area budidaya rumput laut $K$ alvarezii
\end{abstract}

Kata Kunci: Alga, Karaginan, Kualitas air, Patok dasar, Pasang surut.

\begin{abstract}
Seaweed cultivation can be carried out in waters that have environmental conditions suitable for seaweed habitat. Kappaphycus alvarezii is a type of red algae seaweed that is classified as carrageenan-producing. $K$. alvarezii are cultivated in Indonesian waters, including on Sumbawa Island. K.alvarezii seaweed cultivation began again in 2020 in the coastal waters of Jelenga, located in West Sumbawa Regency. The cultivation method used is the bottom off method by utilizing the tidal area which is still submerged in water at the lowest tide. The purpose of this study was to determine the current environmental conditions of the coastal waters of Jelengah for the $K$. alvarezii seaweed cultivation area. These environmental conditions include the water quality of the cultivation location. This study uses a direct survey method at the research site. The results showed that the coastal waters of Jelenga had a temperature range of $29.2-29.8^{\circ} \mathrm{C}, \mathrm{pH} 7.2-7.1$, salinity $32-$ $34 \mathrm{ppt}$, dissolved oxygen 5.2-7.8 $\mathrm{mg} / \mathrm{L}$, nitrate $11-12.7 \mathrm{mg} / \mathrm{L}$, phosphate $0.004-0.12 \mathrm{mg} / \mathrm{L}$, and current velocity $7.2-16 \mathrm{~cm} / \mathrm{sec}$. This study concludes that the current environmental conditions of the Jelengah coastal waters are by the required environment as a seaweed $K$. alvarezii cultivation area.
\end{abstract}

Keyword: Algae, Carageenan, Water quality, Bottom off method, Intertidal.

\section{Pendahuluan}

Pantai Jelenga terletak di pulau Sumbawa tepatnya di Kecamatan Jereweh Kabupaten
Sumbawa Barat Provinsi Nusa Tenggara Barat. Pantai Jelenga dikenal dengan keindahan pantai pasir putih dan kondisi 
perairan yang dapat dikatakan bersih. Aktivitas manusia di pantai Jelenga diantaranya wisata, penangkapan ikan dengan pancing dan budidaya rumput laut. Budidaya rumput laut telah dilakukan masyarakat setempat sejak tahun 2006 namun terhenti pada tahun 2010. Kegiatan budidaya rumput laut muncul kembali pada tahun 2020 dan baru dilakukan oleh satu kelompok pembudidaya. Jenis rumput laut yang dibudidayakan adalah Kappaphycus alvarezii strain warna coklat dan warna hijau. K.alvarezii merupakan alga merah yang pada umumnya dibudidayakan di perairan Indonesia termasuk perairan di Pulau Sumbawa. Eem et al. (2014) menerangkan bahwa K.alvarezii memiliki habitat di perairan pantai dan perairan yang memiliki terumbu karang. Habitat khasnya adalah daerah yang mendapatkan gerakan air yang kontinyu dengan variasi suhu harian yang kecil.

Metode budidaya rumput laut saat ini yang digunakan adalah metode lepas dasar atau dikenal dengan metode patok dasar. Wijayanto et al. (2011) menjelaskan bahwa metode patok dasar merupakan metode budidaya dengan konstruksi kerangka dasar adalah patok yang terbuat dari kayu, bambu, besi atau beton yang ditempatkan di dasar perairan. Bibit rumput laut K.alvarezii diperoleh dari Dinas Kelautan dan Perikanan Kabupaten Sumbawa Barat dan Balai Pengembangan Budidaya Laut (BPBL) Sekotong Lombok. Bibit yang digunakan merupakan bibit dengan kualitas yang baik dengan harapan pertumbuhan dan hasil panen maksimal. Pertumbuhan rumput laut K.alvarezii dipengaruhi juga oleh kondisi lingkungan perairan lokasi budidaya. Lokasi budidaya harus memiliki kondisi lingkungan sebagaimana habitat aslinya. K.alvarezii hidup menempel pada subtrat perairan berupa karang atau batuan dan menyukai gerakan air yang kontinyu. Tujuan penelitian ini adalah untuk mengetahui kondisi lingkungan perairan pantai Jelengah saat ini untuk area budidaya rumput laut $K$. alvarezii.

\section{Metode Penelitian}

\subsection{Waktu dan Tempat}

Penelitian ini dilakukan di pantai Jelenga Kecamatan Jereweh Kabupaten Sumbawa Barat, Provinsi Nusa Tenggara Barat. Penelitian dilakukan pada bulan Mei sampai dengan April 2021.

\subsection{Metode Penelitian}

Metode penelitian yang digunakan adalah metode survei langsung di lapangan. Hasil penelitian dianalisa secara deskriptif dan dibahas berdasarkan berbagai literatur terkait kondisi lingkungan lokasi budidaya rumput laut $K$. alvarezii.

\subsection{Prosedur Penelitian}

Variabel penelitian yang diukur adalah parameter kualitas air yaitu suhu, salinitas, $\mathrm{pH}$, oksigen terlarut, nitrat dan phosphat. Alat dan bahan yang digunakan adalah aquades, kamera, alat tulis, termometer air, refraktometer, bola plastik, tali rafia, $\mathrm{pH}$ pen, Disolved Oxigen (DO) meter, nitrat kit, dan phospat kit.

\section{Hasil dan Pembahasan}

Kondisi perairan pantai Jelenga secara visual dapat dikatakan bersih dan memiliki air yang jernih dengan gerakan air yang kontinyu. Berikut adalah nilai parameter kualitas air di pantai Jelenga sebagai area budidaya rumput laut $K$. alvarezii (Tabel 1).

Tabel 1. Nilai Parameter Kualitas Air Perairan Pantai Jelenga

\begin{tabular}{lcl}
\hline \multicolumn{1}{c}{ Parameter } & Nilai Kisaran & \multicolumn{1}{c}{ Referensi } \\
\hline Suhu $\left({ }^{\circ} \mathrm{C}\right)$ & $29,2-29,8$ & $26-32(\mathrm{BSN}, 2011)$ \\
Salinitas $(\mathrm{ppt})$ & $32-34$ & $28-34(\mathrm{BSN}, 2011)$ \\
$\mathrm{pH}$ & $7,2-7,1$ & $7-8,5(\mathrm{BSN}, 2011)$ \\
Oksigen Terlarut $(\mathrm{mg} / \mathrm{L})$ & $5,2-7,8$ & $5-10 \mathrm{mg} / \mathrm{L}(\mathrm{Cokkrowati}$ et al., 2020$)$ \\
Nitrat $(\mathrm{mg} / \mathrm{L})$ & $11-12,7$ & $>0,04(\mathrm{BSN}, 2011)$ \\
Fosfat $(\mathrm{mg} / \mathrm{L})$ & $0,004-0,12$ & $>0,1(\mathrm{BSN}, 2011)$ \\
Arus $(\mathrm{cm} /$ detik) & $7,2-16$ & $20-40($ Yusup, 2015) \\
\hline
\end{tabular}

Kondisi lingkungan perairan pantai Jelenga memiliki kisaran nilai kualitas air sebagaimana Tabel 1. Gerakan air pantai
Jelenga relatif tenang namun kontinyu yaitu 7,2 - 16 sehingga hal tersebut mendukung nilai suhu perairan yang stabil sebagaimana 
suhu alami perairan laut yaitu $29,2^{\circ} \mathrm{C}$ sampai dengan $29,8^{\circ} \mathrm{C}$. Gerakan air tersebut juga mendukung pasokan oksigen terlarut dalam air yaitu berkisar antara 5,2-7,8 $\mathrm{mg} / \mathrm{L}$. Nilai salinitas air perairan Indonesia bagian timur termasuk perairan Pulau Sumbawa, lebih tinggi dari salinitas perairan Jawa. Nilai salinitas air pantai Jelenga adalah 32-34 ppt. Nilai nitrat berkisar $11-12,7 \mathrm{mg} / \mathrm{L}$ dan fosfat 0,004-0,12 mg/L, nilai tersebut disukung oleh dasar perairan yang merupakan karang mati.

\subsection{Suhu}

Suhu adalah derajat panas perairan dan merupakan parameter kualitas air yang menjadi kunci dari perubahan nilai parameter kualitas air lainnya. Jika nilai suhu berubah maka nilai parameter kualitas air lainnya juga berubah. Nilai suhu perairan dipengaruhi oleh penetrasi cahaya matahari yang masuk kedalam perairan. Suhu perairan juga dipengaruhi oleh pergerakan air dan cahaya matahari. Nilai kisaran suhu perairan pantai Jelenga adalah $29,2-29,8^{\circ} \mathrm{C}$ dan masih di kisaran rentang suhu yang ditetapkan oleh BSN (2011), yaitu $26-32^{\circ} \mathrm{C}$. Yudasmara (2014) menjelaskan bahwa suhu yang baik untuk rumput laut adalah $27,5^{\circ} \mathrm{C}$.

Suhu mempengaruhi proses fisiologi rumput laut, yaitu pada proses fotosintesis, respirasi, dan metabolisme sehingga dapat berpengaruh terhadap pertumbuhannya. Kordi (2010) menyebutkan bahwa suhu air yang sesuai untuk rumput laut jenis Eucheuma adalah $20-30^{\circ} \mathrm{C}$. Aslan (1998) menjelaskan bahwa suhu yang baik untuk pertumbuhan rumput laut jenis K.alvarezii adalah berkisar $25-30^{\circ} \mathrm{C}$. Arisandi et al. $\left(2011^{\mathrm{a}}\right)$ menjelaskan hasil penelitiannya bahwa, K.alvarezii yang diberi perlakuan suhu $20^{\circ} \mathrm{C}-40^{\circ} \mathrm{C}$ tidak menunjukkan perbedaan yang nyata terhadap rata-rata pertumbuhan hariannya. Orbita (2013) menjelaskan bahwa laju pertumbuhan $K$. alvarezii berkorelasi positif dengan suhu dengan kisaran suhu $28-31^{\circ} \mathrm{C}$.

\subsection{Salinitas}

Salinitas merupakan kandungan garam terlarut dalam air dan pada air laut nilai salinitas dipengaruhi oleh suhu perairan. Semakin tinggi nilai suhu perairan maka semakin tinggi nilai salinitas air karena penguapan yang terjadi akan semakin tinggi dan air semakin memekat. Kisaran nilai salinitas air pantai Jelenga adalah 32-34 ppt, sedangkan kisaran yang dibutuhkan untuk K.alvarezii menurut BSN (2011) adalah 32-34 ppt. Loban (1994) dalam Arisandi $\left(2011^{\mathrm{b}}\right.$ ) menjelaskan bahwa jika kisaran salinitas air laut melebihi kisaran yang ditoleransi oleh alga, maka pertumbuhan dan perkembangan sel alga berbanding linier dan terbalik dengan kenaikan salinitas. Salinitas menurunkan laju pertumbuhan melalui pengurangan laju pembesaran sel pada talus. Pengaruh nilai salinitas tinggi terhadap pertumbuhan dan perubahan struktur alga adalah ukuran stomata lebih kecil, sehingga penyerapan hara dan air berkurang.

\subsection{Derajat Keasaman (pH)}

Derajat keasaman perairan atau disebut dengan $\mathrm{pH}$ merupakan kadar ion dalam air pada perairan. Nilai $\mathrm{pH}$ dipengaruhi oleh jumlah oksigen terlarut dalam air, semakin rendah nilai oksigen terlarut maka nilai $\mathrm{pH}$ semakin rendah dan sebaliknya. Nilai $\mathrm{pH}$ yang dibutuhkan oleh rumput laut K.alvarezii yang dibudidayakan menurut BSN (2011) adalah 78 ,5. Kisaran nilai $\mathrm{pH}$ di perairan pantai Jelenga adalah 7,2-7,1 sesuai dengan yang dikehendaki oleh rumput laut K.alvarezii. Aslan (1998) menjelaskan bahwa rumput laut dapat hidup pada kisaran $\mathrm{pH}$ 6,8-9,6. Lundsor (2002) menjelaskan bahwa kisaran $\mathrm{pH}$ yang optimal bagi pertumbuhan rumput laut K.alvarezii adalah yaitu 7-9. Nur et al. (2016) menjelaskan hasil penelitiannya bahwa derajat keasaman yang rendah dapat menekan pertumbuhan $K$. alvarezii yang dibudidayakan dalam penelitiannya.

\subsection{Oksigen Terlarut}

Oksigen terlarut pada umumnya juga disebut dengan Dissolved Oxygen (DO) merupakan jumlah oksigen yang terlarut dalam air. Oksigen terlarut di perairan pantai berasal dari oksigen hasil fotosintesis yang dilakukan oleh fitoplankton dan tumbuhan air yang hidup di dasar dan kolom perairan. Oksigen terlarut juga berasal dari difusi udara bebas yaitu gerakan air yang menimbulkan oksigen di udara bebas masuk ke perairan. Rumput laut merupakan tumbuhan air yang dapat melakukan fotosintesa dan menghasilkan oksigen. Namun untuk proses fisiologis pertumbuhannya, rumput laut tetap membutuhkan oksigen terlarut dalam air. 
Nilai oksigen terlarut di perairan pantai Jelenga berkisar 5,2-7,8 mg/L, dengan acuan standar untuk budidaya adalah $5-10 \mathrm{mg} / \mathrm{L}$ (Cokrowati et al., 2020). Atmanisa et al., (2020) menjelaskan bahwa pertumbuhan rumput laut K.alvarezii membutuhkan oksigen terlarut sebesar 2-4 $\mathrm{mg} / \mathrm{L}$, namun pertumbuhan akan lebih optimal jika oksigen terlarut berada di atas $4 \mathrm{mg} / \mathrm{L}$.

\subsection{Nitrat}

Nitrat merupakan unsur hara makro yang dibutuhkan oleh rumput laut $K$. alvarezii untuk pertumbuhannya. Hasil analisis konsentrasi nitrat di perairan pantai Jelenga berkisar antara 11-12,7 mg/L. Menurut BSN (2011), kadar fosfat yang baik untuk budidaya rumput laut yaitu >0,04 mg/L. Kadar nitrat di perairan pantai Jelenga melebihi standar yang dibutuhkan untuk pertumbuhan rumput laut, sehingga perairan pantai Jelenga dapat digunakan sebagai area budidaya rumput laut. Patahiruddin (2020) menjelaskan bahwa nutrien dibutuhkan untuk pertumbuhan rumput laut. Nutrien tersebut diantaranya adalah nitrat yang merupakan unsur hara yang penting alga, dan tumbuhan air serta menentukan tingkat kesuburan perairan.

\subsection{Fosfat}

Fosfat terlarut dalam perairan yang dapat di manfaatkan oleh rumput laut adalah dalam bentuk bentuk orthofosfat. Orthofosfat merupakan nutrien penting yang dibutuhkan rumput laut dalam proses pertumbuhannya. Kadar fosfat diperairan pantai Jelenga berkisar antara 0,004-0,12 $\mathrm{mg} / \mathrm{L}$. BSN (2011) menetapkan bahwa kisaran fosfat yang dapat mencukupi pertumbuhan rumput laut adalah > $0,1 \mathrm{mg} / \mathrm{L}$. Pauwah et al. (2020); Fatmawati et al. (1998); Abdan et al. (2013); Ariyati et al. (2007) menjelaskan bahwa kandungan fosfat perairan yang mendukung pertumbuhan K.alvarezii adalah 0,01-0,051 mg/L. Apabila kekurangan $K$. alvarezii kekurangan fosfat maka akan berakibat terakumulasinya lemak dalam sel.

\subsection{Arus}

Gerakan air di perairan pantai Jelenga relatif tenang namun kontinyu, pantai ini merupakan teluk kecil dari Pulau Sumbawa. Kecepatan arus di perairan pantai Jelenga adalah 7,2-16 cm/detik. Kecepatan arus berperan pada aktivitas pergerakan nutrien di peraairan. Arus membawa pasokan oksigen dan nutrisi yang dibutuhkan untuk pertumbuhan rumput laut di perairan. Pauwah et al. (2020) menyebutkan bahwa kisaran yang baik untuk budidaya rumput laut sebesar $20-40 \mathrm{~cm} / \mathrm{s}$. Arus dan gerakan air diperlukan K.alvarezii yang dibudidayakan untuk membersihkan kotoran, lumpur dan biota lain yang menempel pada talus. Arus akan membersihkan talus sehingga talus dapat menyerap sinar matahari dan nutien dalam perairan secara maksimal.

\section{Kesimpulan dan Saran}

Kondisi perairan pantai Jelenga saat ini sesuai dengan lingkungan yang disyaratkan sebagai area budidaya rumput laut K.alvarezii.

Penelitian yang perlu dilakukan selanjutnya adalah budidaya rumput laut dengan berbagai metode sebagai alternatif metode untuk mengatasi perubahan kondisi iklim yang ekstrim

\section{Daftar Pustaka}

Aslan, L.M. (1998). Budidaya Rumput Laut. Penerbit Kanisius. Yoyakarta

Ariyati, R.W., L. Sya'rani, A. Endang. (2007). The Suitability Analysis of Karimunjawa and Kemujan Island Territory for Seaweed Culture Site using Geographical Information System. Jurnal Pasir Laut, 3(1):27-45.

Arisandi, A., Marsoedi, H. Nursyam, A. Sartimbul. $\quad\left(2011^{\mathrm{a}}\right) . \quad$ Kajian Pertumbuhan Kappaphycus alvarezii Hasil Kultur Jaringan pada Perlakuan Suhu yang Berbeda. Jurnal Kelautan, 4(1):77-81.

DOI: https://doi.org/10.21107/jk.v4i1.8 93

Arisandi, A., Marsoedi, H. Nursyam, A. Sartimbul. (2011 $)$. Pengaruh Salinitas yang Berbeda terhadap Morfologi, Ukuran dan Jumlah Sel, Pertumbuhan serta Rendemen Karaginan Kappaphycus alvarezii. Ilmu Kelautan. 16(3):143-150.

DOI: https://doi.org/10.14710/ik.ijms.1 6.3.143-150

Abdan., Rahman dan Ruslaini. (2013). Pengaruh Jarak Tanam terhadap Pertumbuhan dan Kandungan Karagenan Rumput Laut (Kappahycus 
alvarezii) Menggunakan Metode Long Line. Jurnal Mina Laut Indonesia, 3(12): 113-123.

Atmanisa, A., A. Mustarin, dan N. Anni. (2020). Analisis Kualitas Air pada Kawasan Budidaya Rumput Laut Eucheuma cottoni di Kabupaten Jeneponto. Jurnal Pendidikan Teknologi Pertanian, 6(1): 11-22. DOI:10.26858/jptp.v6i1.11275.

[BSN] Badan Standar Nasional. (2011). Produksi Bibit Rumput Laut Kotoni (Eucheuma cottoni). Bagian 1: Metode Lepas Dasar. Jakarta.

Cokrowati, N., N. Diniarti, D.N. Setyowati, A. Mukhlis. (2020). Pertumbuhan Rumput Laut Hasil Kultur Jaringan Kappaphcus alvarezii. Jurnal of Fisheries and Marine Research. Volume 4(1):61-65. DOI: http://dx.doi.org/10.21776/ub.jfmr 2020.004.01.9

Eem, L.P., J. Tan, R. Adibi, dan S.M. Phang. (2014). A Guide to Kappaphycus and Eucheuma Seaweed in Malaysia. University of Malaya. Malaysia.

Fatmawati, Sutikno, Hardjosuwarno. (1998). Kesesuaian Budidaya Rumput Laut (Eucheuma) di Wilayah Perairan Laut Daerah Tingkat II Kotabaru Kalimantan Selatan. BPPS-Universitas Gadjah Mada, 11(3):305-321.

Kordi, M.G.H. (2010). Kiat Sukses Budidaya Rumput Laut di Laut dan Tambak. Lily Publisher. Yogyakarta.

Lobban, C.S dan P.J. Harrison. (1994). Seaweed Ecology and Physiology. Cambridges University Press. 366 pp.

Lundsor, E. (2002). Eucheuma Farming in Zanbibar. Broadcast System, an Alternative Method for Seaweed Farming. Candidata Scientiarium in Marine Biology. University of Bergen.

Nur, A.I., S. Husain, dan Patang. (2016). Pengaruh Kualitas Air terhadap Produksi Rumput Laut (Kappaphycus alvarezii). Jurnal Pendidikan Teknologi Pertanian. 2: 27-40. DOI: https://doi.org/10.26858/jptp.v2i1. 5151.
Orbita, M.L.S. (2013). Growth rate and Carrageenan Yield of Kappaphycus alvarezii (Rhodophyta, Gigartinales) Cultivated in Kolambugan. Lanao del Norte. Mindanao. Philippines. $A A C L$ Bioflux, 5 (3) :128-139.

Patahiruddin. (2020). Pengaruh Nitrat Subtrat terhadap Pertunbuhan Rumput Laut Gracilaria verrucosa di Tambak Budidaya Desa Lare-Lare Kabupaten Luwu Sulawesi Selatan. Fisheries of Wallacea Journal, 1(1): 1-8.

Pauwah, A., M. Irfan, dan Fatma, M. (2020). Analisis Kandungan Nitrat dan Fosfat untuk Mendukung Pertumbuhan Rumput Laut Kappahycus alvarezii yang Dibudidayakan dengan Metode Longline di Perairan Kastela Kecamatan Pulau Ternate Kota Ternate. Hemyscyllium, 1(1): 10-22.

Wijayanto, T., M. Hendri, dan R. Aryawati. (2011). Studi Pertumbuhan Rumput Laut Eucheuma Cottonii dengan Berbagai Metode Penanaman yang Berbeda di Perairan Kalianda Lampung Selatan. Maspari Journal, 3:51-57.

Yudasmara, G.A. (2014). Budidaya Anggur Laut (Caulerpa racemosa) Melalui Media Tanam Rigid Quadrant Nets Berbahan Bambu. Jurnal Sains dan Tekhnologi. 3(2).

Yusup, S., K. Ma'ruf, M.B. Abdul. (2017). Pengaruh Bobot Awal yang Berbeda terhadap Pertumbuhan dan Kandungan Keragenan Rumput Laut Kappaphycus alvarezii yang Terserang Epifit dalam Rakit Jaring Apung. Jurnal Media Akuatika. 2(4): 509-518. DOI: http://dx.doi.org/10.33772/jma.v2 i4.4356. 